\title{
Effects of chlorpromazine and atropine on the maintenance of Hurwitz avoidance '
}

HARRY L. CHIPMAN, Jr. MARY WASHINGTON COLLEGE OF THE UNIVERSITY OF VIRGINLA

Adult male hooded rats were observed on a previously acquired Hurwitz avoidance task under these conditions: injections of saline, chlorpromazine, and atropine. Significant reductions in avoidance were noted under drug conditions. Since the dosages used were below reported behaviorally effective levels, the Hurwitz procedure would seem to have value as a test of drug effectiveness. Further, differential effects of chlorpromazine and atropine were seen.

Hurwitz (1964) described a discriminated avoidance procedure for the rat which shares many features of the Sidman paradigm: short duration cycling shock and a bar press operant. Hurwitz proposed this procedure to overcome reported difficulties in obtaining bar press avoidance. Further, he suggested that it should be of value to physiological psychology. Indeed, one would expect that the Hurwitz procedure could be applied to electrical stimulation of the brain and to psychopharmacological investigation. However, no such applications are to be found in the literature since 1964.

The study reported here sought to examine the effect of chlorpromazine (CPZ) and of atropine on the malntenance of Hurwitz avoidance behavior. The use of chlorpromazine was prompted by a previous study (Chipman, 1966). Atropine was included for comparison purposes because its action on the brainstem reticular formation differs from that of chlorpromazine (Bradley, 1963).

Subjects

Nine adult male hooded rats of the Long-Evans strain were the Ss. They were maintained on ad lib conditions. Previously, each had served in a Hurwitz avoidance conditioning experiment and had attained $70 \%$ avoldance.

\section{Apparafus}

A commercially available test chamber for rats (Scientific Prototype) with a PM speaker and a lever mounted in the same wall was used. The chamber's grid floor was wired for scrambled shock. The shock scrambler circuit was designed and constructed in the Purdue University Psychology Department shops. The test chamber was housed in a sound-attenuating cubicle which was equipped with a blower in the roof and a 7-1/2 W lamp on the rear wall at the top. The lamp was on continuously during testing.

The output of a click generator delivered to the PM speaker provided the conditioned stimulus. The intensity of this rapidly clicking sound was $56 \mathrm{~dB}$. All contingencies were controlled by Grason-Stadler automatic programming equipment housed in an adjacent room.

\section{Design}

Three treatments were administered to each $S$ in a balanced order specified by a latin square. These were: saline (control); CPZ, $2 \mathrm{mg} / \mathrm{kg}$; and atropine, $10 \mathrm{mg} / \mathrm{kg}$. All injections were $.5 \mathrm{ml}$ and were given IP just prior to testing. The drug dosages are below the reported range of behavioral effectivenesz for the rat (Barnes \& Eltherington, 1965).

The procedure for each trial was essentially that described by Hurwitz (1964). The original procedure was modified as follows: An auditory CS and a $1 \mathrm{~mA}$ shock were used. The contingencies for all trials were: intertrial interval (ITI) $\mathbf{- 5}$ sec; interstimulus interval (ISI)-15 sec; shock duration-.2 sec; and intershock interval-15 sec. Each $S$ was run daily for $1 \mathrm{~h}$ until a day to day consistency was obtained. At that time the $S$ was run under the assigned treatment. The experiment was concluded when all Ss had recelved all treatments.

\section{Results}

Three measures were recorded for each treatment session: total responses with the CSpresent (responses), total response occurring during ISI (avoids), and total shocks received (shocks). A percent avoldance score was computed for each treatment condition.

Differences between all pairs of treatment means on responses and shocks were examined by statistical tests for correlated data (Downie \& Heath, 1965). The treatment percent avoidance scores (avoldance) were compared in a similar fashion. The results of all tests are given in Table 1. All tests on avoldance were significant beyond the .01 level. Of the tests on responses, only the one between CPZ and atropine was significant

Table 1 Tests on mean differences between all treatment combinations for each of three measures

\begin{tabular}{llcr}
\hline Combination & Measure & $\begin{array}{c}\text { Mean } \\
\text { Difference }\end{array}$ & $\mathrm{Z}$ \\
\hline & Responses & 36.66 & 1.14 \\
Saline/ & Avoidance & 9.20 & 7.96 \\
Atropine & Shocks & 15.55 & 2.99 \\
& & & \\
& Responses & 46.77 & 1.74 \\
Saline/ & Avoidance & 15.10 & 11.51 \\
CPZ & Shocks & 43.77 & 2.82 \\
& & & \\
& Responses & 82.33 & 2.20 \\
Atropine/ & Avoidance & 5.90 & 4.34 \\
CPZ & Shocks & 29.33 & 1.66 \\
\hline
\end{tabular}

Note: Avoidance computation is the difference between two percentages 
(.05 level). However, the reverse was true for tests on shocks (.01 level).

Discussion

The administration of CPZ and of atropine produced a significant reduction in avoidance and an increase in shocks. It would not seem reasonable to attribute these effects to a reduction in motor performance since there was no significant difference between saline and drug treatments on responses. Further, the dosages used are below those reported as behaviorally effective. The results of this study suggest that the Hurwitz procedure as employed here may be a sensitive test of drug effects.

Differential effects of $\mathrm{CPZ}$ and atropine were noted in the results of the present study. CPZ produced a greater reduction in avoidance than atropine. However, no such effect was seen in the shocks comparison. Further, the departures from the saline response level were in opposite directions. To what are these differences to be attributed? This is a difficult question to answer, since there is no assurance that the dosages were comparable. However, a possible explanation might be found in the differential action of these compounds on the brainstem reticular formation. Additional experiments are planned to investigate this question. References

BARNES, C. D., \& ELTHERINGTON, L. G. Drug dosage in laboratory animals: a handbook. Berkley: University of California Press, 1965.

BRADLEY, P. B. Phenothiazine derivations. In W. S. Root \& F. G. Hofman (Eds.), Physiological pharmacology. New York: Academic Press, 1963. Pp. 417-447.

CHIPMAN, H. L. The differential effects of conditioned stimulus intensity and chlorpromazine on avoidance. Psychon. Sci, 1966, 6, 413414.

DOWNIE, N. M., \& HEATH, R. W. Basic statistical methods. (2nd ed.) New York: Harper \& Row, 1965.

HURWITZ, H. M. B. Method for discriminative avoidance training. Science, 1964, 145, 1070-1071.

Note

1. Animals and test apparatus were provided by Dr. W. C. Black, Purdue University, Department of Psychology. Grason-Stadler programming equipment was loaned to the author by Dr. V. H. Denenberg, Purdue University, Department of Psychology. The experiment was conducted while the author was an instructor at Purdue University. 